\title{
Dislocation Motion in Copper under Small Stresses*
}

\author{
By Michio Ohta**, Yasuhiro Miura*** and Sadakichi Kitajima***
}

\begin{abstract}
Dislocation motion in copper was studied by dislocation-etching before and under loading, and also after unloading. Parallelepiped copper single crystals had a dislocation density of approximately $1 \times 10^{3} / \mathrm{cm}^{2}$ after thermal cyclic annealing. The dislocation etching under load was accomplished by hanging a small weight on the specimen in the etching solution.

Principal results are as follows:

(1) Dislocation locking stress due to impurity atoms was estimated to be less than $0.46 \mathrm{~g} / \mathrm{mm}^{2}$, assuming that impurity atoms act only as pinning points.

(2) Lattice frictional stress for dislocation motion was evaluated to be, at most, $0.20 \mathrm{~g} / \mathrm{mm}^{2}$, from the consideration of force balance on a bowed-out dislocation near the crystal surface.

(3) Both grown-in and multiplied dislocations were observed to move backward by unloading. Fresh dislocations made a back motion more easily.

(4) From an examination of the distance of dislocation motion and the average distance between grown-in forest dislocations, it is suggested that the main obstacle to moving dislocations is forest dislocations.
\end{abstract}

(Received August 14, 1972)

\section{Introduction}

The nature of obstacles to moving dislocations is one of the most fundamental problems in the field of crystal plasticity. In pure crystals the following are considered to be the main obstacles; (1) impurity atoms, (2) intrinsic lattice frictional stress, and (3) interaction between dislocations. Impurity atoms will cause both a locking force and a frictional force to dislocations. It has been reported that an intrinsic latttice frictional stress is a controlling obstacle to moving dislocations in diamond type crystals or ionic crystals such as $\mathrm{Ge}, \mathrm{Si}$ or $\mathrm{LiF}^{(1)}$

A relatively small number of works have been reported on soft metals like copper, probably because of the difficulties in growing highly perfect crystals and in specimen handling technique. But it will be safe to say that in pure copper an intrinsic lattice frictional stress is negligibly small, judging from the already known experimental results ${ }^{(2)(3)}$ which show a large dislocation velocity and a small temperature and strain rate dependency of the macroscopic yield stress.

One can, nevertheless, not generally neglect any one of the above possible obstacles. The nature of the controlling obstacles to moving dislocations should be substantially clarified before the yielding mechanisms are discussed, since the two could be closely related to each other. Earlier, Young ${ }^{(4)}$ and Marukawa $^{(3)}$ reported that the locking of dislocations by impurity atoms is the most important factor in

* This paper was originally published in the Journal of Japan Institute of Metals, 36 (1972), 908. (in Japanese)

** Faculty of Engineering, Kyushu University, Fukuoka. Present address: Faculty of Dentistry, Kyushu University, Fukuoka, Japan.

*** Faculty of Engineering, Kyushu University, Fukuoka, Japan.

(1) W. G. Johnston and J. J. Gilman: J. Appl. Phys., 30 (1959), 129.

(2) K. Marukawa: Tech. Rep. I. S. S. P., A (1966), No. 222. determining the yield stress.

Young(5), from etch pit observations on bent copper, concluded that grown-in dislocations were locked by impurity atoms and that a resolved shear stress larger than $4 \mathrm{~g} / \mathrm{mm}^{2}$ was necessary for a dislocation to break up the impurity atmosphere. Marukawa $^{(2)}$ reported, also, from etch pit observations on bent copper that several percents of grown-in dislocations started moving at a resolved shear stress of $5 \mathrm{~g} / \mathrm{mm}^{2}$. He observed a back motion of a dislocation on removal of a resolved shear stress of $10 \mathrm{~g} /$ $\mathrm{mm}^{2}$, less than the shear stress for dislocation multiplication, in the crystal in which dislocation multiplication already occurred. But this was not the case with an annealed crystal.

Petroff and Washburn ${ }^{(6)}$ reported that the minimum shear stress for dislocation motion was $2.5 \mathrm{~g} /$ $\mathrm{mm}^{2}$, from the observation of dislocation motion in annealed crystals. Tinder and Washburn ${ }^{(7)}$ observed an apparent elastic limit of $2 \mathrm{~g} / \mathrm{mm}^{2}$ through a microstrain experiment and concluded that the minimum shear stress for dislocation motion should be close to the value $2 \mathrm{~g} / \mathrm{mm}^{2}$.

One of the present authors ${ }^{(8)}$ observed the dislocation motion at a resolved shear stress as low as $0.2 \mathrm{~g}$ / $\mathrm{mm}^{2}$.

In the present work, behaviors of dislocations in highly perfect copper under a small tensile stress was carefully studied and the nature of obstacles to moving dislocations was discussed.

(3) K. Marukawa: Bull. Japan Inst. Metals, 8 (1969), 569.

(4) F. W. Young, Jr.: J. Appl. Phys., 33 (1962), 963.

(5) F. W. Young, Jr.: J. Appl. Phys., 32 (1961), 1815.

(6) P. Petroff and J. Washburn: J. Appl. Phys., 37 (1966), 4986.

(7) R. F. Tinder and J. Washburn: Acta Met., 12 (1964), 129.

(8) S. Kitajima, H. Tonda and H. Kaieda: Proc. Int. Conf. on Strength of Metals and Alloy, Suppl. to Trans. JIM, 9 (1968), p. 740 


\section{Experimental Procedures}

Electrolytic high purity copper (nominally $99.999 \%$ $\mathrm{Cu}$ ) was melted in a low ash graphite crusible (ash; $20 \mathrm{ppm})$ in vacuum $\left(2 \times 10^{-5} \mathrm{mmHg}\right)$ by a vertical electric resistance furnace and a single crystal was grown by the Bridgman method with a furnacetraveling speed of $6 \mathrm{~cm} / \mathrm{hr}$. The as-grown single crystal was a cylinder, approximately $20 \mathrm{~mm}$ in diameter and $10 \mathrm{~cm}$ long with its one end being conical. The cylinder was cut and polished by an acid saw and an acid polisher into two parallelepipeds with one pair of their surfaces parallel to $\{111\}$. Straight nitric acid and a solution $\left(\mathrm{H}_{3} \mathrm{PO}_{4}: 40 \%, \mathrm{HNO}_{3}: 50 \%, \mathrm{CH}_{3} \mathrm{COOH}\right.$ : $10 \%$. $\mathrm{HCl}: 0.01 \sim 1.5 \%$ ) were used for the acid sawing and the acid polishing, respectively.

The parallelepipeds were then subjected to thermal cyclic annealing ${ }^{(9)}$ so as to reduce the dislocation density and subgrain boundaries. After the thermal cyclic annealing the specimens were completely free from subgrain boundary. The final dimensions, orientations of axes and dislocation density of the specimens are shown in Table 1.

Young's etchant ${ }^{(10)}$ was used for No. 1 specimen and Livingston's ${ }^{(11)}$ for No. 2 specimen. A tensile

Table 1 Dimension, initial dislocation density $\left(N_{0}\right)$ and orientation of the specimen axis.

\begin{tabular}{l|c|c|c}
\hline \hline & $\begin{array}{c}\text { Dimension } \\
\left(\mathrm{mm}^{3}\right)\end{array}$ & $N_{0}\left(\mathrm{~cm}^{-2}\right)$ & Orientation \\
\hline No. 1 & $5.8 \times 4.6 \times 50$ & $1.21 \times 10^{3}$ & $\langle 110\rangle-14^{\circ} \rightarrow\langle 112\rangle$ \\
No. 2 & $5.3 \times 3.9 \times 50$ & $1.47 \times 10^{3}$ & $\langle 110\rangle-15^{\circ} \rightarrow\langle 112\rangle$ \\
\hline \hline
\end{tabular}

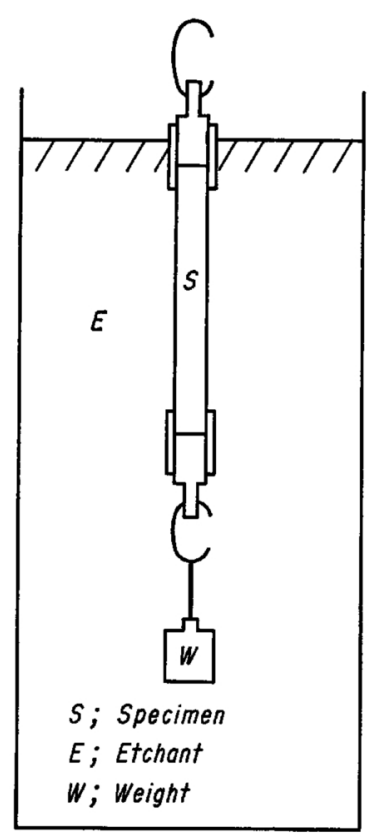

Fig. 1 Specimen under load.

(9) S. Kitajima M. Ohta and H. Kaieda: J. Japan Inst. Metals, 32 (1968), 164.

(10) F. W. Young, Jr.: J. Appl. Phys., 32 (1961), 192.

(11) J. D. Livingston: J. Appl. Phys., 31 (1960), 1071. (a)

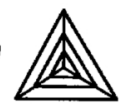

(b)
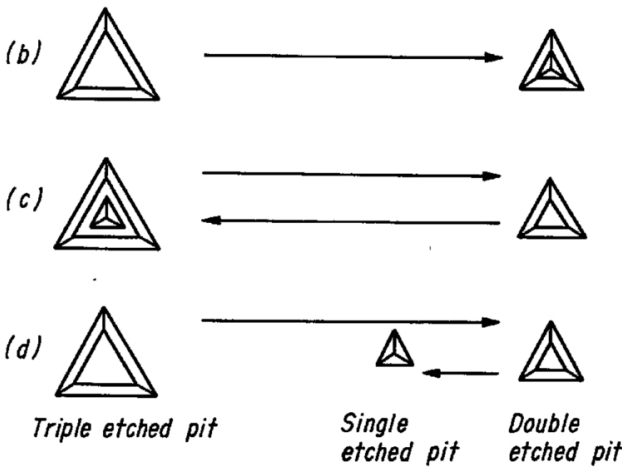

Fig. 2 Single, double and triple etched pits.

stress was applied along the specimen axis by hanging a small weight. Specimens were etched before being stressed (the first etching). Then a dead load was applied by hooking up a small weight carefully which was in the etching solution (the second etching) (Fig. 1.). Dislocation sites under the stress could be revealed. Then the load was released, while the specimen was still in the etchant (the third etching). Thus one can see if dislocations made any "back motion." The etching time was twenty five seconds in each etching stage.

The triple etched specimen was brought to an optical microscope and the whole $\{111\}$ surface $(5 \times 30$ $\mathrm{mm}^{2}$ ) was photographed with a magnification of 100 .

For No. 1 specimen, the resolved shear stress in the primary slip system $\left(\tau_{p}\right)$ was $0.61 \mathrm{~g} / \mathrm{mm}^{2}$, using a $40-\mathrm{g}$ weight as a dead load. For No. 2 specimen, a 20 -g weight was used and $\tau_{p}$ was $0.40 \mathrm{~g} / \mathrm{mm}^{2}$. In Fig. 2 , etch pits of different sizes and types after triple etching were schematically shown. Great care was expended in specimen handling throughout the experimental procedures.

\section{Results}

\section{No. 1 specimen}

In an area of $10 \mathrm{~mm}^{2}$, the number of grown-in dislocations (the largest pits with a flat or sharp bottom), $N_{0}$, was 113. Among them $33\left(N_{v}\right)$ was flat bottomed. This means $\left(N_{v} / N_{0}\right) \times 100 \approx 30(\%)$ of grown-in dislocations were moved by the stress, $\tau_{p}=$ $0.61 \mathrm{~g} / \mathrm{mm}^{2}$. The actual value in percentage may be even larger, because some of the largest sharp pits might have been confused with those pits of dislocations which fully moved back to their original positions by unloading (Fig. 2(c)). It was not easy to locate the smallest sharp pits which corresponded to the sites where dislocations had moved back by unloading, partly because of shortness of the time of the third etching.

One example where a dislocation fully moved back to its original position by unloading was observed in the critical slip system (Photo. 1), which was a case of 


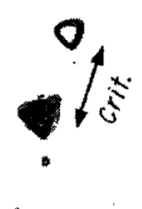

. 1

Photo. 1 Dislocation returned to the original point. (Specimen No. 1)

Fig. 2(c).

\section{No. 2 specimen}

For this specimen, grown-in dislocation sites were recorded before applying a load by taking micrographs of the surface.

After a third etching, a few groups of multiplied dislocations, rows of double etched pits, were observed along the primary slip direction near one end of the specimen. This indicates that a certain unknown

Table 2 Number of etch pits and percentage of moved dislocations. Triple etched pits correspond to the sites of grown-in dislocations. Double etched pits correspond to the sites of dislocations which have moved by loading. Single etched pits correspond to the sites of dislocations which have made a back motion by unloading.

\begin{tabular}{l|l|l}
\hline \hline $\begin{array}{l}\text { Number of } \\
\text { triple etched } \\
\text { pits }\end{array}$ & $\begin{array}{l}163\left(N_{0}: \text { total }\right) \\
33\left(N_{v}: \text { flat bottomed }\right)\end{array}$ & $\left(N_{v} / N_{0}\right) \times 100=20.2$ \\
$\begin{array}{l}\text { Number of } \\
\text { double etched } \\
\text { pits }\end{array}$ & $59\left(N_{0}:\right.$ total $)$ & $\left(N_{v}:\right.$ flat bottomed $)$ \\
$\begin{array}{l}\text { Number of } \\
\text { single etched } \\
\text { pits }\end{array}$ & 27 & $\left(N_{v} / N_{0}\right) \times 100=33.9$ \\
\hline
\end{tabular}

Table 3 Distance of dislocation motion.

\begin{tabular}{|c|c|c|c|c|c|c|c|c|}
\hline \multicolumn{3}{|c|}{$\begin{array}{c}\begin{array}{c}\text { Primary slip } \\
\text { system } \\
\phi=0.404\end{array} \\
\end{array}$} & \multicolumn{3}{|c|}{$\begin{array}{c}\text { Critical slip } \\
\text { system } \\
\phi=0.303 \\
\end{array}$} & \multicolumn{3}{|c|}{$\begin{array}{c}\text { Conjugate slip } \\
\text { system } \\
\phi=0.242\end{array}$} \\
\hline $\begin{array}{l}\text { Dislo- } \\
\text { cation }\end{array}$ & $L_{f}(\mu)$ & $L_{b}(\mu)$ & $\begin{array}{l}\text { Dislo- } \\
\text { cation }\end{array}$ & $L_{f}(\mu)$ & $L_{b}(\mu)$ & $\begin{array}{l}\text { Dislo- } \\
\text { cation }\end{array}$ & $L_{f}(\mu)$ & $L_{b}(\mu)$ \\
\hline $\begin{array}{r}1 \\
\text { No. } \\
3 \\
4 \\
5 \\
6 \\
7 \\
8 \\
9 \\
10 \\
11 \\
12 \\
13\end{array}$ & $\begin{array}{r}387 \\
139 \\
110 \\
327 \\
267 \\
260 \\
190 \\
73 \\
347 \\
373 \\
20 \\
60 \\
47\end{array}$ & $\begin{array}{r}0 \\
0 \\
0 \\
0 \\
60 \\
17 \\
0 \\
0 \\
13 \\
143 \\
0 \\
0 \\
0\end{array}$ & $\begin{array}{r}\text { No. } 1 \\
2 \\
3 \\
4 \\
5 \\
6 \\
7\end{array}$ & $\begin{array}{r}33 \\
20 \\
10 \\
110 \\
227 \\
20 \\
40\end{array}$ & $\begin{array}{l}0 \\
0 \\
0 \\
0 \\
0 \\
0 \\
0\end{array}$ & No. $\frac{1}{2}$ & $\begin{array}{l}17 \\
10\end{array}$ & $\begin{array}{l}0 \\
0\end{array}$ \\
\hline Ave. & 200 & 18 & Ave. & $\overline{66}$ & 0 & Ave. & $\sqrt{14}$ & 0 \\
\hline
\end{tabular}

$L_{f}$ : Distance of forward motion.

$L_{b}$ : Distance of backward motion.

$\phi:$ Schmid factor.

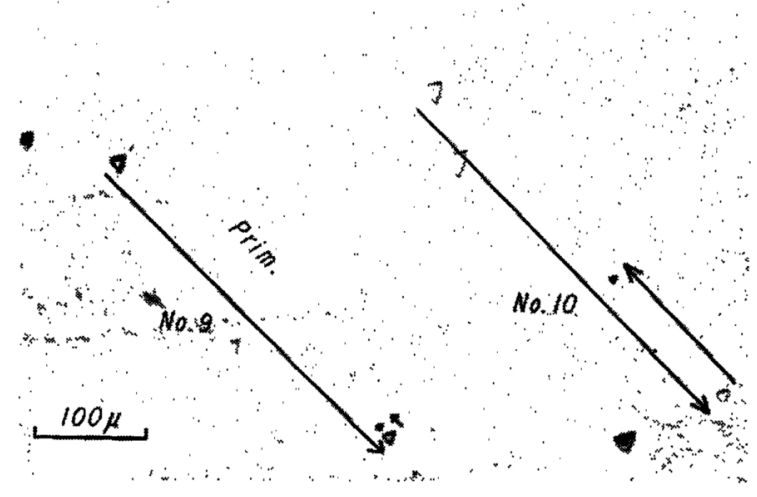

Photo. 2 Dislocation partly returned. (Specimen No. 2)

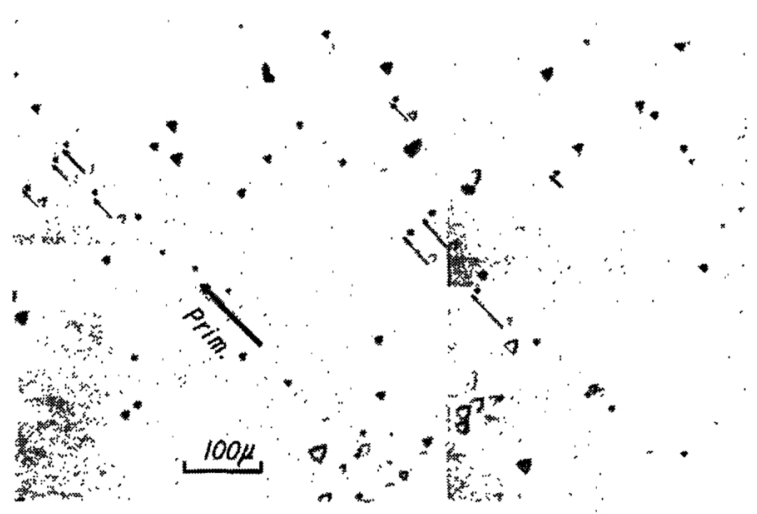

Photo. 3 Back motion of multiplied dislocations. Some examples are marked with arrows. (Specimen No. 2)

amount of undesired local stress was applied before loading, probably during the microscope operation. Therefore, motion of grown-in dislocations was studied in the regions near the opposite end of the specimen where the effects of the undesired local stress would be negligible.

In Table 2, the numbers of etch pits of each size and type are shown. The distances of forward and backward motions were different from one dislocation to the other as shown in Table 3, but the average distance of the forward motion was larger in the slip system with a larger Schmid factor.

Examples of the motion of dislocations in the primary slip system are given in Photo. 2. Two dislocations that had moved approximately the same distance by loading, made a back motion of different length by unloading. Photograph 3 shows a back motion of multiplied dislocations. Those dislocations seemed to make a back motion more easily than grown-in dislocations. Dislocation multiplication was seen to have occurred in localized band regions.

\section{Discussions}

\section{No. 1 specimen}

In No. 1 specimen, thirty percents of grown-in dislocations moved at a resolved shear stress of $0.61 \mathrm{~g} /$ $\mathrm{mm}^{2}$. The tensile axis of the specimen was nearly parallel to $\langle 123\rangle$, and a single slip was favored.

From a crystallographic examination of the speci- 
men, it can be seen that there are dislocations of nine different slip systems operative under the tensile stress. The resolved shear stress in the primary slip system was much larger than in the secondary slip systems. So, if $1 / 9 \approx 11 \%$ of the grown-in dislocations had moved, it will be safe to say that most dislocations in the primary slip system would have moved, assuming that grown-in dislocations had random Burgers vectors and were in arbitrary slip planes.

Thus, even if there had been any impurity locking, the locking stress would be less than $0.61 \mathrm{~g} / \mathrm{mm}^{2}$. The resolved shear stress in the critical slip system was the second largest to the primary $\left(\tau_{\text {crit }} / \tau_{p}=0.75\right.$, where $\tau_{\text {crit }}$ is the resolved shear stress in the critical slip system) and it is also quite possible that all the dislocations in the critical slip system had moved as well as those in the primary slip system. In this case, the dislocation locking stress by impurity atoms can be less than $0.46 \mathrm{~g} / \mathrm{mm}^{2}$.

This value is much smaller than those obtained by other workers. $^{(3)(5) \sim(7)}$ This discrepancy is probably due to the difference in the amount of impurity atoms and also due to the difference in the length of the mobile dislocation segment. In the present work, a thermal cyclic annealing was employed to reduce dislocation density. Therefore, the dislocation segment lying on a single slip plane is expected to be longer than those in the case of isothermal annealing which other workers used. ${ }^{(12)}$

The difference in the mode of stressing, initial dislocation density and subgrain size could also be the cause of the discrepancy.

\section{No. 2 specimen}

Before the known stress, $\tau_{p}=0.40 \mathrm{~g} / \mathrm{mm}^{2}$, was applied, the undesired local stress $\tau_{x}$ was applied. But in this case, a sharp-bottomed, triple etched pit corresponds to a dislocation which had not moved at all or had moved by loading and fully restored by unloading of $\tau_{p}$ or $\tau_{x}$. The smallest pit shows the site where a dislocation had moved back by unloading of the stress $\tau_{p}=0.40 \mathrm{~g} / \mathrm{mm}^{2}$.

Let us consider an equilibrium configuration of a dislocation near the surface under an external stress and after the removal of the stress (Fig. 3). Here, $\tau_{a}$ is the external stress, $\tau_{f}$ is the lattice frictional
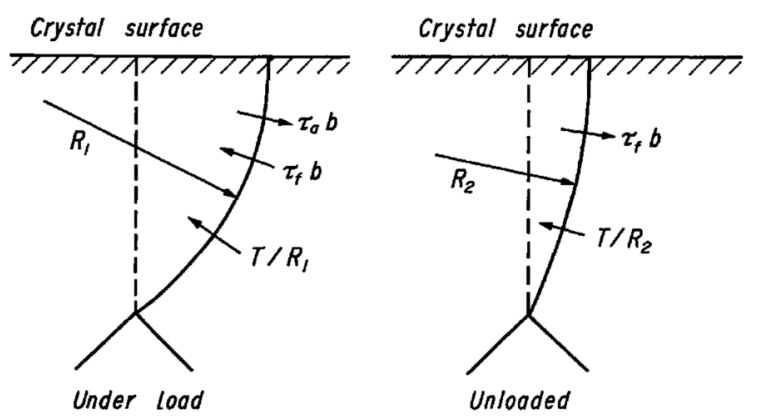

Fig. 3 Equilibrium dislocation configuration.

(12) M. Ohta, S. Kitajima, K. Aoyagi and H. Kaieda: J. Japan Inst. Metals, 35 (1971), 929. stress, and $T=G b^{2} / 2$ is line tension of a dislocation.

A bowed-out dislocation by loading would take the same configuration as its original one after unloading, provided that $\tau_{f}$ is negligibly small. Forest dislocations or some other defects might act as pinning points and prevent the dislocation from going back to the original position. Several cases of the back motion were observed in the primary slip system (Photo. 2).

Considering the force balances in Fig. 3, one obtains

$$
\begin{aligned}
\tau_{a} b & =\tau_{f} b+T / R_{1} \text { (under stress) } \\
\tau_{f} b & =T / R_{2} \text { (after unloading), }
\end{aligned}
$$

where $R_{1}$ and $R_{2}$ are the radii of the bowed-out dislocation under load and after unloading, respectively. The condition that $R_{2}<R_{1}$ yields $T / R_{2}<T / R_{1}$. Consequently one gets $\tau_{a} b>2 \tau_{f} b$ and $\tau_{f}<\tau_{a} / 2=0.20$ $\mathrm{g} / \mathrm{mm}^{2}$. This result is not unreasonable, because one of the present authors and co-workers previously observed $^{(8)}$ a dislocation motion at a resolved shear stress smaller than $0.2 \mathrm{~g} / \mathrm{mm}^{2}$. If a back motion took place in the critical slip system, an even smaller value for $\tau_{f}$ would be obtained $\left(\tau_{f}<\tau_{\text {crit }} / 2=0.12 \mathrm{~g} / \mathrm{mm}^{2}\right)$.

In Table 3, the distances of dislocation motion in different slip systems were shown. The distance varies with individual dislocations, from $20 \mu$ to $400 \mu$ in the primary slip system and from $10 \mu$ to $230 \mu$ in the critical slip system. The distance of dislocation motion should be closely related to the distance between obstacles, assuming that the moving dislocations were stopped by them. (12) $^{\text {(1) }}$

The actual average distance of dislocation motion may be even greater than those in Table 3, because some dislocations have moved too far distances to be identified or moved out of the crystal. The average distance between forest dislocations estimated from the initial dislocation density, $N_{0}=1.47 \times 10^{3} / \mathrm{cm}^{2}$, is $260 \mu$, which is comparable to the actual average distance of dislocation motion. This strongly suggests that the main obstacle to moving dislocations may be the interaction force between dislocations. The fact that the distance of motion varies with individual dislocations suggests that the lengths and distribution of grown-in dislocations are rather nonuniform.

In Photo. 2, two dislocations (No. 9 and No. 10 in Table 3), which had moved comparable distances under a stress, made back motion of different lengths
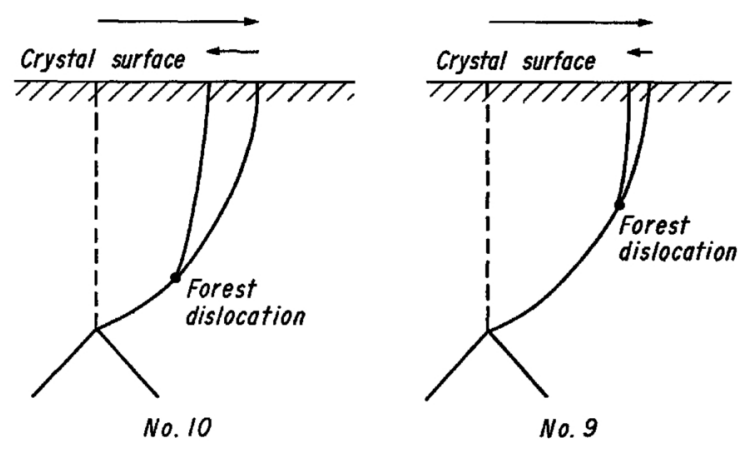

Fig. 4 Trapping of dislocation by forest dislocation. 
by unloading. This could be easily understood in such a way that the dislocation No. 9 had been trapped by a dislocation at a closer distance from the crystal surface than the dislocation No. 10 (as schematically shown in Fig. 4).

Photograph 3 shows an area where a dislocation multiplication took place. It is seen that many multiplied dislocations made a back motion. Most of the multiplied dislocations may not be trapped by forest dislocations, because distances between the multiplied dislocations are smaller than those between forest dislocations. The motion of those dislocations is controlled by the long range elastic interaction between dislocations. Therefore, by unloading, the multiplied dislocations would make a back motion more easily than grown-in dislocations.

This may be why Marukawa ${ }^{(2)}$ observed a back motion only on multiplied dislocations, but not on grown-in dislocations.

\section{Conclusions}

A small stress was applied to highly perfect copper single crystals and observations were made on dislocation motion through an etch pit technique. The following were concluded.
(1) Dislocation locking stress due to impurity atoms was estimated to be less than $0.46 \mathrm{~g} / \mathrm{mm}^{2}$, assuming that impurity atoms act only as pinning points.

(2) Lattice frictional stress for the dislocation motion was evaluated to be, at most, $0.20 \mathrm{~g} / \mathrm{mm}^{2}$, from the consideration of stress balance on a bowedout dislocation near the crystal surface.

(3) Both grown-in and multiplied dislocations were observed to move backward by unloading. Multiplied dislocations made a back motion more easily.

(4) From the examination of the distance of dislocation motion and the average distance of the grown-in dislocations, it is suggested that main obstacle to moving dislocations is forest dislocations.

\section{Acknowledgments}

The authors wish to express their deepest gratitudes to Professor Hiroya Kaieda for his continuous support through the present investigation. They also wish to express their appreciations to Mr. Akira Kiyonaga for his assistance in the experimental parts of the present work. 